\title{
Changes of Cerebral Hemodynamics and Oxygenation in Unstable Septic Newborns during Exchange Transfusion
}

\author{
YOSHIHIKO MURAKAMI, YUSHIRO YAMASHITA, TOSHIHIRO NISHIMI, \\ TOSHIRO INOUE, TOYOJIRO MATSUISHI AND HIROHISA KATO

\begin{abstract}
Department of Pediatrics and Child Health, Kurume University School of Medicine,
\end{abstract} \\ Kurume 830-0011, Japan
}

\begin{abstract}
Summary: We investigated the effect of a two-way exchange transfusion on cerebral hemodynamics and oxygenation in 3 neonates using near infrared spectroscopy (NIRS). A total of 4 exchange transfusions (ET) for the treatment of sepsis were performed. Cerebral oxyhemoglobin concentrations $\left(\mathrm{HbO}_{2}\right)$ increased immediately after commencing with $\mathrm{ET}$ by $8.82 \pm 3.46$ (mean \pm SD) $\mu \mathrm{mol} / \mathrm{l}$, which persisted throughout the ET. Total hemoglobin concentrations ( $\mathrm{HbT}$ ) simultaneously increased by $8.92 \pm 3.81$ (mean \pm SD) $\mu \mathrm{mol} / \mathrm{l}$. No changes in cerebral deoxyhemoglobin concentrations $(\mathrm{HbR})$ and cytochrome $\mathrm{aa}_{3}\left(\mathrm{Cytaa}_{3}\right)$ were observed. In one occasion, however, $\mathrm{HbR}$ increased markedly and $\mathrm{HbO}_{2}$ decreased immediately after $\mathrm{ET}$ had begun, thus $\mathrm{HbT}$ remained slightly increased compared to the 3 other occasions. The extension of periventricular echogenecity was observed after ET by cranial ultrasound scan in this patient and periventricular leukomalacia was confirmed by autopsy. We conclude that a two-way exchange transfusion increases cerebral blood volume and improves cerebral oxygen delivery. Furthermore NIRS was useful in monitoring changes in cerebral hemodynamics and oxygenation in unstable septic neonates.
\end{abstract}

Key words near-infrared spectroscopy, exchange transfusion, cerebral circulation, cytochrome $\mathrm{aa}_{3}$, sepsis, periventricular leukomalacia

\section{INTRODUCTION}

Exchange transfusion (ET) was first introduced in 1951 by Diamond for the treatment of newborn infants with hemolytic disease and hyperbilirubinemia. Over the last decade, indications for ET have significantly decreased due to decreased incidence of hemolytic disease and the preventive and therapeutic use of phototherapy in newborns. However, ET still has been an indispensable therapy in sick infants with severe hyperbilirubinemia and sepsis unresponsive to other therapies.

It is now possible to obtain information noninvasively and continuously on cerebral hemodynamics and oxygenation using near infrared spectroscopy (NIRS) [1-5]. Nevertheless, there have been a few reports regarding effects of cerebral hemodynamics and oxygenation on ET [4]. Van de
Bor reported that relative changes in cerebral blood volume were primarily associated with changes in mean arterial blood pressure, followed by changes in arterial oxygen tension and in exchange cycle duration in stable term and near-term infants [4]. They used the "pull push" method. The aim of this study was to assess changes in cerebral hemodynamics and oxygenation in unstable septic newborn infants undergoing two-way exchange transfusions using NIRS.

\section{PATIENTS AND METHODS}

Three neonates with sepsis who were admitted to the neonatal intensive care unit at Kurume University Hospital between 1994 and 1995 were enrolled in this study. Parental consent was obtained before enrollment in all cases. Patients' characteristics are 
TABLE 1.

Clinical summary of 3 patients

\begin{tabular}{llll}
\hline Patient & 1 & 2 & 3 \\
\hline Sex & Male & Male & Female \\
G. W. & 33 & 39 & 36 \\
B. W. (in grams) & 1700 & 2300 & 2078 \\
Apgar score & unknown & $5 / 7$ & $6 / 8$ \\
E. T. (in days) & 22 & 4 & $11 \& 13$ \\
Indication & Sepsis & Sepsis & Sepsis \\
Intracranial insults & PVE & Hydrocephalus & PVE \\
before E. T. & & & \\
Other & PDA, ASD & Congenital & Omphalocele \\
& PS, CHF & Toxoplasmosis & \\
\hline
\end{tabular}

E. T.: exchange transfusion; G. W.: gestational weeks; B. W.: birth weight; PVE: periventricular echogenecity; PDA: patent ductus arteriosus; ASD: atrial septal defect; PS: pulmonary stenosis; CHF: congestive heart failure
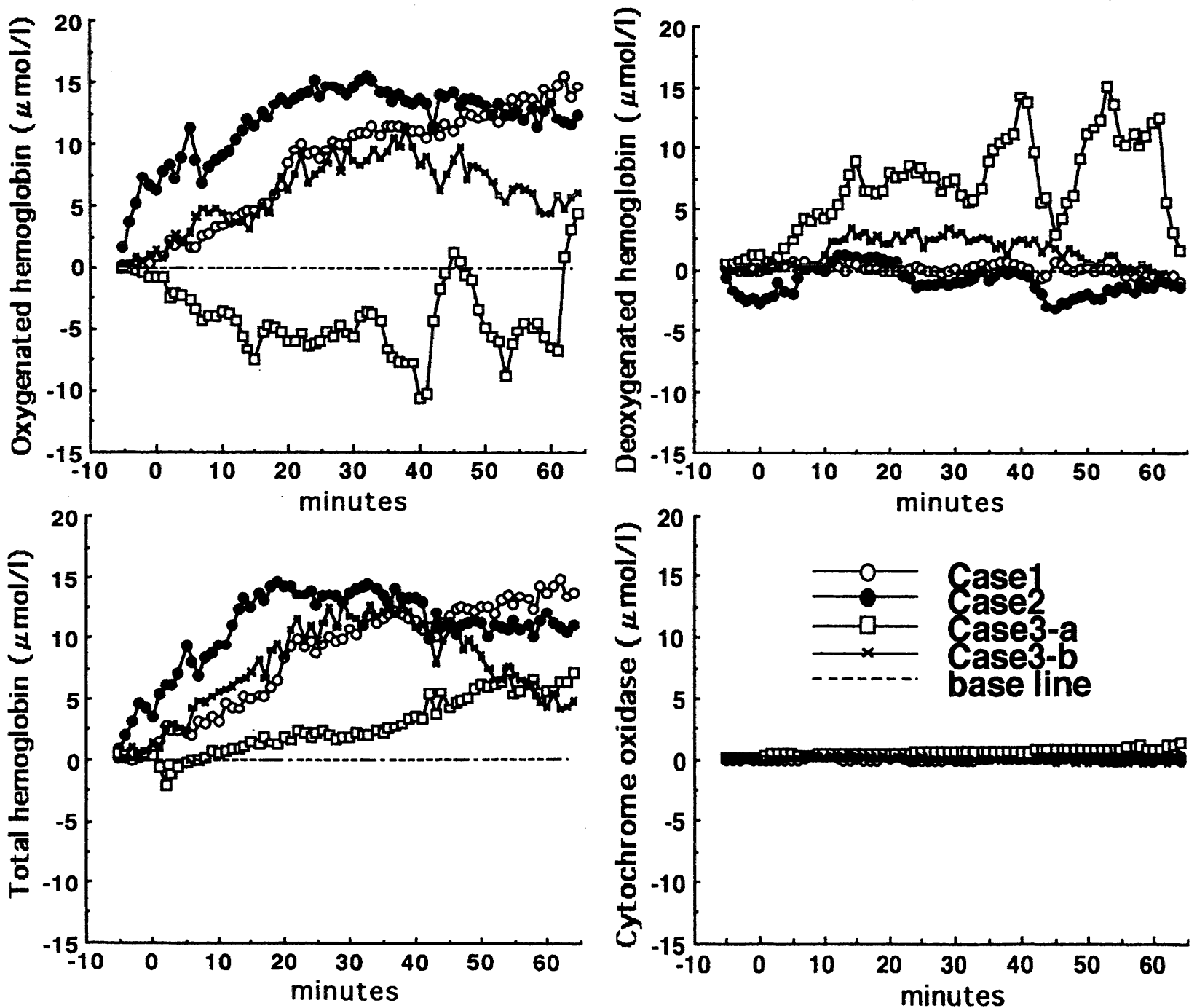

Fig. 1. Changes in NIRS variables during exchange transfusion.

Changes in cerebral oxygenated, deoxygenated, and total hemoglobin, and cytochrome oxidase during 4 exchange transfusions in 3 patients. Oxygenated and total hemoglobin increased during exchange transfusions, except for on one occasion. Cytochrome $\mathrm{aa}_{3}$ was stable. 
shown in Table 1 . We used the two-way exchange method, in which the umbilical artery was used for withdrawal, and a vein for infusion to eliminate the swings in blood volume and pressure. In all neonates, $20-30 \mathrm{ml} / \mathrm{kg}$ of blood was exchanged during each cycle.

In all patients, NIRS (NIRO-500; Hamamatsu Photonics KK, Hamamatsu, Japan), with a sampling time of $10 \mathrm{sec}$, was performed continuously from 5 min before beginning until the end of ET. This technique depends on measuring the characteristic absorption within cerebral tissue of near-infrared light by the two natural chromophores (hemoglobin and cytochrome $\mathrm{aa}_{3}$ ) concentrations and the proportions of their oxygenated and deoxygenated forms. Algorithms have been developed to convert absorption changes into changes in oxygenated hemoglobin concentration $\left(\mathrm{HbO}_{2}\right)$, deoxygenated hemoglobin concentration (HbR), total hemoglobin concentration $\left(\mathrm{HbT}=\mathrm{HbO}_{2}+\mathrm{HbR}\right)$, and oxidized cytochrome $\mathrm{aa}_{3}$ concentration $\left(\mathrm{Cytaa}_{3}\right)$. The transmitting and receiving optodes were placed symmetrically in the usual positions on the anterior fontanelle. The interoptode distance used in our study was $4.5 \mathrm{~cm}$. We assumed an optical length of 4.4 times the interoptode distance in consideration of the scattering of light in brain tissue [3,5]. Transcutaneous carbon dioxide tension $\left(\mathrm{TcPCO}_{2}\right.$, Micro Gas 7640 , Kontron, Watford, England) and arterial oxygen saturation $\left(\mathrm{SpO}_{2}, \mathrm{~N}-200\right.$ Pulse Oximeter, Nellcor, Hayward, CA, USA) were continuously recorded. Blood pressure was intermittently measured by a neonatal blood pressure monitor (901, ATOM, Tokyo, Japan).

Cranial ultrasound scans were performed on all neonates using a $5 \mathrm{MHz}$ probe at least twice before ET and numerous times after ET.

\section{RESULTS}

All ET were performed for the treatment of sepsis. ET was performed twice in patient 3 at 11 (patient 3-a) and 13 days (patient 3-b) after birth. The

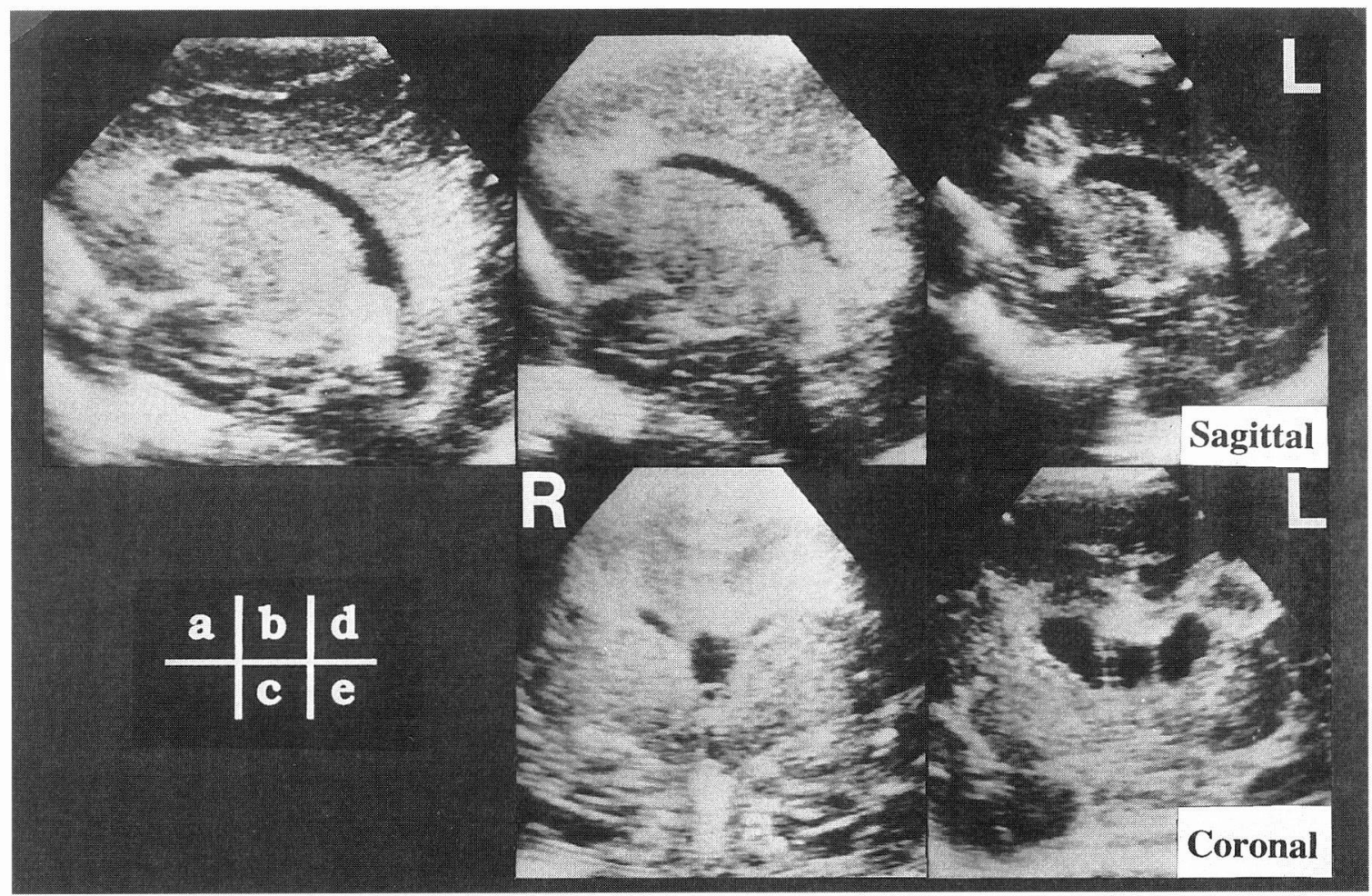

Fig. 2. Sequential cranial ultrasound findings in patient 3-a.

a: Mild periventricular echogenecity was observed only around the trigone of the bilateral lateral ventricles $1 \mathrm{~h}$ before exchange transfusion.

b, c: Periventricular echogenesity extended in area; periventricular frontal and trigone, more prominent on the left side, recognized $12 \mathrm{hs}$ after exchange transfusion.

d, e: Two weeks after exchange transfusion, echogenesity decreased and cystic lesions in the periventricular left frontal and trigone areas were revealed. Progression of ventricular dilatation was also observed. 
gestational ages of the 3 infants were 33,36 , and 39 weeks, respectively. The birth weights were 1700 , 2078, and 2300 grams, respectively. All infants were mechanically ventilated and the setting of each mechanical ventilation was not changed during NIRS monitoring except for in patient 3-a, whose respiration worsened during ET because of underlying hazy lung disease, whicn was a complication of supplemental fat parenteral alimentation and omphalocele. Therefore, ET was interrupted and patient 3-a was manually ventilated for one treatment. All patients received dopamine and antibiotics intravenously. Hemoglobin did not change between pre- and postET; blood pressure was stable during ET (data not shown). Cranial ultrasound before ET demonstrated mild periventricular echogenesity in patients 1 and 3 , and moderate ventricular dilatation in patient 2 .

Data on 4 occasions of NIRS before and during ET are shown in Fig. 1. On 3 occasions (patients 1, 2 and 3-b), a significant increase in $\mathrm{HbO}_{2}$ and $\mathrm{HbT}$ compared to pre-ET was observed, whereas HbR and Cytaa $_{3}$ remained stable. HbT increased from 0.27 to 12.90 (mean \pm S.D. $8.92 \pm 3.81) \mu \mathrm{mol} / \mathrm{l}$, with an increase of $\mathrm{HbO}_{2}$ from 0.50 to 12.03 (mean \pm S.D. $8.82 \pm 3.46) \mathrm{mol} / \mathrm{l}$. HbR ranged from -1.30 to 1.80 (mean \pm S.D. $0.15 \pm 0.94) \mu \mathrm{mol} / \mathrm{l}$, and $\mathrm{Cytaa}_{3}$ ranged from 0.00 to 0.23 (mean \pm S.D. $0.11 \pm 0.23$ ) $\mu \mathrm{mol} / \mathrm{l}$.

In patient 3-a, we observed an entirely different pattern of NIRS variables; HbR markedly increased, $\mathrm{HbO}_{2}$ decreased simultaneously, and $\mathrm{HbT}$ increased subsequently after ET. In this case, extension of periventricular echogenesity was confirmed by cranial ultrasound scans after ET (Fig. 2) and periventricular leukomalacia was pathologically confirmed by autopsy. However, there were also no changes of $\mathrm{Cytaa}_{3}$ in this patient.

\section{DISCUSSION}

We evaluated cerebral hemodynamics and oxygenation during ET in unstable septic newborn infants by using NIRS. The most striking findings were the increase of $\mathrm{HbO}_{2}$ and $\mathrm{HbT}$ on 3 occasions; increases were observed immediately after ET and subsequently, in 2 cases (patient 1 and 2) remained at the high levels compared to the baseline for $30 \mathrm{~min}$ after ET. Measurements returned to the baseline at the end of ET in one case (patient 3-b).

Wyatt et al. reported that relative changes in cerebral blood volume (dCBV) are to be calculated as follows: $\mathrm{dCBV}=\mathrm{HbT} \times 0.89 /$ large vessel $\mathrm{Hb}$ concentration [7]. A good relation between changes in cerebral blood flow (CBF) and $\mathrm{dCBV}$ has been demonstrated $[7,8]$. In this study, alterations of $\mathrm{HbT}$ may suggest increase of $\mathrm{dCBV}$ or CBF. It is possible that blood pressure, $\mathrm{PaCO}_{2}$, volume, and speed of exchange transfusion might influence increases of $\mathrm{HbT}$, specifically CBV. These factors are not likely responsible for alterations in $\mathrm{HbT}$, because 1) ET was performed by the two-way method, 2) no correlations between $\mathrm{HbT}$ and blood pressure were found, and 3) hemoglobin did not change before and after ET. No changes in $\mathrm{PaCO}_{2}$ before and after ET were found, except on one occasion (patient 3-a). These findings suggest that primary changes observed by NIRS during ET were due to an increase of $\mathrm{HbO}_{2}$ with the improvement of cerebral oxygen delivery.

Patient 3-a had a omphalocele, complicated sepsis, hazy lung disease, and mild periventricular echogenesity in the parieto-occipital area, observed by cerebral ultrasound scans before ET. He had an entirely different NIRS pattern during ET; HbR increased immediately and $\mathrm{HbO}_{2}$ decreased after ET. In this case, cerebral ultrasound scans revealed periventricular echogenic lesions confined to bilateral trigone before ET, but they extended to around the left frontal horn of the lateral ventricles immediately after ET. Subsequently, these lesions were confirmed as periventricular leukomalacia (PVL) by autopsy. Interestingly, the second ET performed 2 days after the first ET in patient 3 showed the same NIRS pattern as those seen in patients 1 and 2. The $\mathrm{PaCO}_{2}$ in patient 3-a increased gradually $20 \mathrm{~min}$ after beginning ET and finally increased to more than $40 \mathrm{mmHg}$ at the end of ET, as compared to the beginning of ET. Changes of HbT in patient 3-a may probably be due to an increase of $\mathrm{CBF}$ with an increase in $\mathrm{PaCO}_{2}$.

Unlike the report by Van de Bor et al., who used the "pull push" ET method, changes in cerebral blood volume observed in this study were not associated with changes in mean arterial blood pressure. This is because we used the two-way ET method, which is superior to the "pull push method" in unstable neonates because blood pressure and cerebral blood volume were not subject to radical changes. Liem et al. recently reported that blood transfusion resulted in an increase of $\mathrm{HbO}_{2}, \mathrm{HbT}$, and $\mathrm{Cytaa}_{3}$ in preterm infants with anemia, whereas isovolemic hemodilution in polycythemic infants resulted in decrease of these 3 variables [5].

NIRS provides useful information about cerebral hemodynamics and oxygenation during ET in 
unstable septic neonates. Monitoring such patterns by these methods may be useful for preventing brain damage.

\section{REFERENCES}

1. Jobsis FF. Noninvasive infrared monitoring of cerebral and myocardial oxygen sufficiency and circulatory parameters. Science 1977; 198:1264-1267.

2. Wyatt JS, Cope M, Delpy DT, Wray S, and Reynolds EOR. Quantitation of cerebral oxygenation and haemodynamics in sick newborn infants by near infrared spectrophotometry. Lancet 1986; 8515:1063-1066.

3. Wyatt JS, Edwards AD, Cope M, Delpy DT, McCormic DC et al. Response of cerebral blood volume to changes in arterial carbon doixide tension in preterm and term infants. Pediatr Res 1991; 29:553-557.

4. Van de Bor M, Benders MJNL, Dorrepaal CA, Van BEl $\mathrm{F}$, and Brand R. Cerebral blood volume changes during exchange transfusions in infants born at or near term. $\mathbf{J}$ Pediatr 1994; 125:617-621.

5. Liem KD, Hopman JCW, Oeseburg B, DeHaan AFJ, and Kollee LAA. The effect of blood transfusion and hemodilution on cerebral oxygenation and hemodynamics in newborn infants investigated by near infrared spectroscopy. Eur J Pediat 1997; 156:305-310.

6. Wyatt JS, Cope M, Delpy DT, Van der Zee P, Arridge S et al. Measurement of optical pathlength for cerebral near infrared spectroscopy in newborn infants. Dev Neurosci 1989; 12:140-144.

7. Pryds O, Greisen G, Skov L, and Friis-Hansen B. Carbon dioxide-related changes in cerebral blood volume and cerebral blood flow in mechanically ventilated preterm neonates: comparison of near infrared spectrophotometry and ${ }^{133}$ Xenon clearance. Pediatr Res 1990; 27:445-449.

8. Skov L, Pryds O, and Greisen G. Estimating cerebral blood flow in newborn infants: comparison of near infrared spectroscopy and ${ }^{133} \mathrm{Xe}$ clearance. Pediatr Res 1991; 30:570-573. 